In the March issue of the NSW Public Health Bulletin, a number of articles examined the relationship between periodontal disease and systemic health. This has stimulated a great deal of interest, and consequently the Bulletin has sought appraisals of the principal references supporting these claims. Christine Roberts and Charles Algert from the NSW Centre for Perinatal Health Services Research have reviewed the paper that suggests that periodontal infection may be a risk factor for preterm birth. They question: 'How strong is the evidence?' Geoffrey Tofler and Anthony Kull from the Department of Cardiology at the Royal North Shore Hospital have reviewed the papers that infer a link between periodontal and cardiovascular disease in 'Cupid and the Tooth Fairy'.

Contact information for the principal dental officers and directors of public oral health services in NSW is included in this issue.

The fourth and final issue in the oral health series will consider the public health impact of oral diseases on the elderly, public health aspects of oral cancer, workforce issues, the surveillance of oral health and future directions for public oral health research.

\title{
PRIORITY SETTING IN DENTISTRY: PUTTING TEETH INTO THE PROCESS
}

\section{Gavin Mooney}

Central Coast Area Health Service and SPHERe*

Department of Public Health and Community

Medicine, University of Sydney

Glynis Newberry

Central Coast Area Health Service

\section{INTRODUCTION}

In principle, priority setting is simple. In practice, it seems more difficult. In dentistry, it is perhaps easier than in many other health care sectors.

From an economics perspective just two principles are needed to drive any priority-setting exercise: efficiency and equity. Efficiency refers to maximising the good that the available resources can provide. Equity refers to the just distribution of something or other.

However, difficulties arise at the following five levels:

- accepting that these are the necessary and sufficient principles

- defining 'the good' that is to be maximised in pursuing efficiency

- defining 'the something' that is to be justly distributed

- measuring 'the good' and 'the something'

- changing the philosophy of planning.

This article considers these five difficulties and indicates how dentistry on the Central Coast has used Program

* Social and Public Health Economics Research Group
Budgeting and Marginal Analysis (PBMA) to formulate not only its priorities but its philosophy of planning.

\section{PBMA ISSUES}

Accepting efficiency and equity as the only principles Too often, we believe, health service priorities are driven by the size of the problem rather than by a philosophy of 'best buys'. ${ }^{1}$ The former is often couched in terms of needs - usually health needs - and has given rise to a major (and very often unproductive) industry of 'needs assessment', one variation of which is the 'burden of illness' approach promulgated by the World Health Organization and the World Bank. ${ }^{2}$ Assessing community needs and measuring the burden of illness are often more productive of frustration and of unnecessary burdens on the analysts. ${ }^{3}$ They may have some limited relevance to equity, depending on how this is defined, but none to efficiency. Once one has measured total needs (we are not even sure that in principle or in practice such an entity has meaning), there is a requirement to decide what to do with the needs assessed. The principles we would advocate are that any additional resources be allocated in areas of need where the best benefits are to be gained. This is different from allocating resources to maximise the number of needs to be met. In the language of the economist, additional resources should be used efficiently to 'maximise the marginal benefits'.

What is intriguing here is that there is no need to measure total need! If there is an extra $\$ 100,000$ available, then the question is: how best to spend it? That can normally be 
answered in efficiency terms without knowing the totality of needs. Efficiency is concerned with altering the balances of resources - 'on the margin' - until benefit ('the good') cannot be increased further. Equity is concerned with ensuring that any resulting distribution is fair. In neither case is measurement of total need required. What we do need to know is the nature of 'the good' being bought and how fairness is to be conceived.

\section{Defining 'the good'}

What's the good of health care? The answer to this question is frequently interpreted or posited to be health (and health alone). This might be right, and certainly health is a benefit. But is it the only benefit? We doubt it. For example, in December last year, a workshop of senior decision makers at the Central Coast Area Health Service examined perceptions of the principles that drive resource allocation. It emerged that there were concerns beyond simply maximising the health of the population. There was interest in access and in respecting the dignity and autonomy of patients. There were concerns for equity and indeed several other potential effects of health service interventions.

There is no single solution to defining the good. However, it is difficult to see that it is purely health. Whatever it is, we would argue that it is important to try to define it as well as possible.

\section{Defining 'the something' that is to be justly distributed}

The main contenders here are equal health, equal access for equal need, and equal use for equal need. We do not advocate one over another. We do advocate that someone in a decision-making capacity must decide which is most important. Otherwise, the worry is that equity will remain something that all are in favour of in principle but fail to deliver in practice.

\section{Measuring 'the good' and 'the something'}

Clearly, the goal is to do this as well as possible by using the best available evidence. However, we would submit that defining 'the good' and 'the something' should precede the measurement. Too often, it seems that what is measurable becomes 'the good' or 'the something', with the consequence that 'the good' or 'the something' are inappropriately defined.

\section{Changing the philosophy of planning}

In the PBMA philosophy of planning, the emphasis is on the margin. It looks to see whether some movement of resources from one activity or one program to another might result in an increase in the overall amount of good produced.

\section{DENTISTRY ONTHE CENTRAL COAST}

In 1995, a PBMA exercise was conducted in Community Dental Services on the Central Coast. ${ }^{4}$ The study was successful, allowing immediate decisions to be made regarding priority choices in dentistry. The Commonwealth Dental Health Program was discontinued in August 1996, reducing the funds to adult dental services in the Central Coast Area Health Service by $\$ 1.75$ million, or two thirds of the budget for adult dental services. PBMA principles and the prioritised wish lists were revisited (see box). Resources were reallocated from areas of less good (or benefit) to areas where the good was maximised. While the dental services provided for adults in particular were still adversely affected by the budget cuts, revisiting the PBMA approach allowed the effects to be kept to a minimum.

PBMA, as a philosophy of planning, has been picked up by the Central Coast Area Health Service. The dental PBMA led not only to considering the use of PBMA longer term in dentistry, but also in mental health and in allied health. In addition, it has led to an examination of the principles underlying priority setting and resource allocation more generally by the Area Health Service. Most recently, it has led to the Central Coast Area Health Service deciding to pursue PBMA and other health economic exercises by employing a health economist (GM) parttime.

\section{REFERENCES}

1. Wiseman V, Mooney G. Burden of illness estimates for priority setting: A debate revisited. Health Policy 1998: 43; 243-251.

2. Murray C, Lopez A. World Health Organisation, World Bank. Summary-The Global Burden of Disease. Cambridge, Mass: Harvard School of Public Health (for WHO and World Bank), 1996.

3. Mooney G, Irwig L, Leeder S. Priority setting in health care: unburdening from the burden of disease, Aust NZ J Public Health 1997: 21(7); 680-1.

4. Newberry G. Setting Health Priorities: The Use of PBMA by the Central Coast Area Health Service. Gosford: CCAHS, 1996; 5-47. Internal publication.

Further information on PBMA as a means of priority setting and the development of 'wish lists' can be found in two previous issues of the NSW Public Health Bulletin: 'Program Budgeting and Marginal Analysis: a guide to resource allocation' (April 1995; 6[4]: 29-30) and 'Program Budgeting and Marginal Analysis in NSW' (October, 1997; 8[10]: 81-82). These back issues can be obtained from our Web site at www.health.nsw.gov.au/publichealth/phb/phb.html. 